\title{
Classes de perfilhos na composição do índice de área foliar em pastos de capim-elefante
}

\author{
Carlos Augusto Brandão de Carvalho(1), Roberto Oscar Pereyra Rossiello(2), Domingos Sávio Campos Paciullo(3), \\ André Fischer Sbrissia(4) e Fermino Deresz ${ }^{(3)}$
}

\begin{abstract}
(1)Agência Paulista de Tecnologia dos Agronegócios, Pólo Regional do Vale do Paraíba, Av. Professor Manoel César Ribeiro, no 320 , Caixa Postal 07, CEP 12400-280 Pindamonhangaba, SP. E-mail: cabcarva@aptaregional.sp.gov.br (2)Universidade Federal Rural do Rio de Janeiro, Dep. de Solos, BR 465, Km 7, CEP 23890-000 Seropédica, RJ. E-mail: ropr@ufrrj.br (3)Embrapa Gado de Leite, Rua Eugênio do Nascimento, no 610, CEP 36038-330 Juiz de Fora, MG. E-mail: domingos@cnpgl.embrapa.br, deresz@cnpgl.embrapa.br (4)Universidade do Estado de Santa Catarina, Centro Agroveterinário, Dep. de Zootecnia, Av. Luiz de Camões, no 2090, CEP 88520-000 Lages, SC. E-mail: sbrissia@cav.udesc.br
\end{abstract}

Resumo - O trabalho foi conduzido de outubro de 2002 a abril de 2003, em Coronel Pacheco, MG, com o objetivo de avaliar os efeitos da altura do resíduo pós-pastejo $(50$ e $100 \mathrm{~cm})$ sobre a radiação fotossinteticamente ativa (RFA) interceptada pelo dossel e o coeficiente de extinção luminosa; a contribuição relativa de classes de perfilhos (basais e aéreos) sobre o índice de área foliar (IAF) e o acúmulo de forragem (AF), em pastos de capimelefante (Pennisetum purpureum Schum.) cv. Napier manejados com intervalos de 30 dias entre pastejos. Foi usado o delineamento blocos completos ao acaso e um arranjo de parcelas subdivididas com quatro repetições, com alturas de resíduo alocadas nas parcelas e as classes de perfilhos nas subparcelas. O IAF, a interceptação da RFA e o coeficiente de extinção luminosa foram influenciados pela altura do resíduo pós-pastejo. As interceptações da RFA foram maiores no verão do que na primavera, em pastos manejados com resíduo de $100 \mathrm{~cm}$. As variações do IAF e da interceptação da RFA não estiveram associados, durante todos os ciclos de pastejo. O IAF e o AF apresentaram variações sazonais, relacionadas à participação de perfilhos basais e aéreos, na população de perfilhos do pasto.

Termos para indexação: Pennisetum purpureum, acúmulo de forragem, coeficiente de extinção luminosa, interceptação luminosa, altura de resíduo.

\section{Tiller classes on leaf area index composition in elephant grass swards}

\begin{abstract}
The work was carried out at Coronel Pacheco, MG, Brazil, from October 2002 to April 2003 with the objective of evaluating the effects of two post-grazing residues $(50$ and $100 \mathrm{~cm})$ on the interception of photosynthetically active radiation (PAR) and light extinction coefficient; relative contribution of tiller classes (basal and aerial) to leaf area index (LAI) and herbage accumulation of elephant grass swards (Pennisetum purpureum Schum.) cv. Napier subjected to grazing intervals of 30 days. The experimental design was a complete randomized block, and treatments were allocated to experimental units using a split plot arrangement, with four replicates. Post-grazing residues were allocated to plots and tiller classes to sub plots. Sward LAI, PAR interception and light extinction coefficient were affected by heigth of post-grazing residue. The intercepted PAR was higher in the summer than in the spring, with higher values recorded for the $100 \mathrm{~cm}$ residues. Variations in LAI and intercepted PAR were not consistently associated throughout the experimental period. LAI and herbage accumulation showed seasonal variations related to the varying contribution of aerial and basal tillers to sward tiller population.
\end{abstract}

Index terms: Pennisetum purpureum, herbage accumulation, light extinction coefficient, canopy light interception, stubble height.

\section{Introdução}

Entre as plantas forrageiras tropicais, destaca-se o capim-elefante (Pennisetum purpureum Schum.), por sua grande capacidade produtiva e alto valor nutritivo quando manejado sob pastejo (Deresz et al., 2001).
Contudo, novas alternativas de manejo, que possibilitem incrementar a produtividade em ecossistemas de pastagens, devem ser testadas, avaliando-se as respostas morfogênicas, estruturais e ecofisiológicas do dossel, para que os mecanismos condicionantes da produção forrageira possam ser esclarecidos (Nascimento Júnior 
et al., 2004). Avaliações dessa natureza, para capimelefante, são escassas na literatura (Paciullo et al., 2003; Carvalho et al., 2006).

A altura do resíduo e a frequiência de desfolha podem afetar o vigor da rebrota de plantas forrageiras, por intermédio de seus efeitos nas variáveis morfogenéticas (Middleton, 1982), e a melhor combinação entre ambas pode ser diferente para cada componente morfogenético. No Brasil, existem diferentes recomendações para o manejo do resíduo pós-pastejo do capim-elefante (Hilleshein \& Corsi, 1990; Cóser et al., 2001). Apesar de a frequiência de pastejo ter um papel importante na determinação da estrutura do relvado (Carnevalli et al., 2006), muitas vezes as restrições experimentais locais impedem que combinações entre freqüência e intensidade possam ser adotadas, de tal forma que a adoção de apenas uma dessas variáveis, como controle, permite um grau de avanço no conhecimento, que deve ser interpretado com cautela e dentro das limitações impostas pelos tratamentos.

O conhecimento do comportamento das classes de perfilhos (basais e aéreos) do capim-elefante manejado sob regime de pastejo, nas diferentes épocas do ano, é essencial para otimizar o uso do pasto, quando se objetiva maximizar a produção de forragem aproveitada para consumo animal, em razão de suas diferenças em termos de origem, idade, pontos de inserção e interações específicas (Paciullo et al., 2003; Carvalho et al., 2005a, 2005b, 2006). Além disso, essas diferenças, determinariam a contribuição relativa de cada classe no índice de área foliar do pasto, o que poderia ser importante na adoção de estratégias e épocas do pastejo.

O índice de área foliar (IAF), definido como a relação entre a área de folhas e a área de solo ocupada (Watson, 1947), é produto de relações dinâmicas entre as características morfogênicas e estruturais da planta (Lemaire \& Chapman, 1996). Esse índice, quando relacionado à interceptação luminosa, possibilita um melhor entendimento das propriedades morfofisiológicas da comunidade vegetal (Parsons \& Chapman, 1998).

O IAF é definido como ótimo, quando o dossel forrageiro atinge a máxima taxa de crescimento (balanço entre fotossíntese e respiração), porém a produção de forragem é maximizada, quando o balanço entre crescimento e senescência é máximo, situação essa que está associada à condição de dossel, em que $95 \%$ da radiação fotossinteticamente ativa (RFA) incidente é interceptada (Parsons et al., 1983).
Contudo, existem algumas limitações quanto ao uso do IAF como parâmetro para o manejo do pastejo, em razão da possível ocorrência de modificações na arquitetura e na composição botânica do pasto (Brown \& Blaser, 1968; Sheehy \& Cooper, 1973), sobretudo para plantas forrageiras de clima tropical que apresentam grande desenvolvimento do componente colmo (Pinto et al., 2001). Assim, para melhor compreensão da dinâmica do IAF de um dossel forrageiro, torna-se necessário, além da quantificação da área foliar total da pastagem, conhecer como essa área foliar está distribuída na população de plantas.

Uma eficiente utilização da radiação solar, por parte do dossel, requer folhas com alta capacidade fotossintética, interceptação próxima do total da RFA incidente e distribuição favorável da luz interceptada entre as folhas, dentro do dossel (Brougham, 1958; Brown \& Blaser, 1968). As características ligadas à interceptação da RFA incidente são dependentes de fatores estruturais como: densidade foliar (área foliar por volume do dossel) e sua distribuição espacial, bem como do ângulo foliar (Verhagen et al., 1963). Além disso, deve-se considerar que a RFA absorvida pela planta é dependente da qualidade da RFA incidente e da eficiência de absorção (Ea) dessa radiação pelo dossel forrageiro. A relação existente entre a Ea e o IAF pode ser descrita como: $E a=k_{1}\left(1-e^{-k_{2}} I A F\right)$, em que: $k_{1}$ é determinado pelas propriedades óticas das folhas, e o $\mathrm{k}_{2}$ é o coeficiente de extinção luminosa (Lemaire \& Chapman, 1996).

Brown \& Blaser (1968) verificaram valores de $\mathrm{k}_{2}$ de 0,4 a 0,7 , em espécies de folhas mais eretas como azevém-perene (Lolium perenne), cultivares de Cynodon (Cynodon dactylon spp.) e a festuca (Festuca arundinacea Schreb.), e de 0,8 a 1,0, em espécies com folhas mais horizontais como a alfafa (Medicago sativa L.), o capim-pangola (Digitaria decumbens Stent), o trevo-branco (Trifolium repens L.). Valores de 0,35 a 2,44 foram encontrados em estudo com três cultivares de Cynodon por Fagundes et al. (2001), e as diferenças verificadas na literatura, entre e dentro de espécies forrageiras, podem ser atribuídas às diferenças morfológicas das espécies estudadas e de suas respostas às variações na disponibilidade e qualidade da luz dentro do dossel.

Os objetivos deste trabalho foram avaliar o índice de área foliar (IAF), a interceptação e o coeficiente de extinção luminosa e o acúmulo de forragem de perfilhos 
basais e aéreos, em pastos de capim-elefante submetidos a duas alturas de resíduo pós-pastejo $(50$ e $100 \mathrm{~cm})$, durante a estação chuvosa, na Zona da Mata de Minas Gerais.

\section{Material e Métodos}

O trabalho foi realizado no campo experimental da Embrapa Gado de Leite, no Município de Coronel Pacheco, MG, a $21^{\circ} 33^{\prime} \mathrm{S}, 43^{\circ} 6^{\prime} \mathrm{W}$ e $410 \mathrm{~m}$ de altitude, de outubro de 2002 a abril de 2003, em uma área de 1,5 ha de capim-elefante, estabelecido em outubro de 2000.

O solo da área experimental é classificado como Neosolo Flúvico distrófico (Embrapa, 1999). Em setembro de 2002, foi realizada uma análise química do solo, a partir de amostras coletadas à profundidade de $0-20 \mathrm{~cm}$, com os seguintes resultados: $21 \mathrm{~g} \mathrm{~kg}^{-1} \mathrm{de}$ MO; $22 \mathrm{mg} \mathrm{dm}^{-3}$ de P (Mehlich-1); 73,6\% de saturação por bases e pH (água) 6; e 0,24, 6,1, 1,4, 0,06, 2,8, 7,8 e $10,6 \mathrm{cmol}_{\mathrm{c}} \mathrm{dm}^{-3}$ de $\mathrm{K}, \mathrm{Ca}, \mathrm{Mg}, \mathrm{Na}, \mathrm{H}+\mathrm{Al}$, soma de bases e CTC, respectivamente. Durante o período experimental, foram realizadas adubações de manutenção, tendo-se utilizado $300 \mathrm{~kg} \mathrm{ha}^{-1}$ da fórmula 20-5-20 em 5/11/2002 e em 17/1/2003, além de $200 \mathrm{~kg} \mathrm{ha}^{-1}$ de sulfato de amônio em 11/3/2003.

O clima da região, de acordo com a classificação de Köppen, é do tipo Cwa (mesotérmico) e definido como temperado-chuvoso no verão e com inverno seco entre junho e setembro. Os dados climáticos foram coletados no posto meteorológico do Campo Experimental, a cerca de $1.000 \mathrm{~m}$ da área experimental. Nos meses de novembro de 2002 e janeiro de 2003, foram registradas elevadas precipitações ( 246 e $351 \mathrm{~mm}$, respectivamente), que excederam bastante os valores médios dos últimos 40 anos (1960-1999), característicos da região (148 mm em novembro e $245 \mathrm{~mm}$ em janeiro). As menores insolações foram verificadas durante os meses de novembro, dezembro e janeiro com 5,7, 5,3 e 4,2 horas por dia. Os valores médios de temperatura do ar foram mais elevados durante o verão $\left(24,2^{\circ} \mathrm{C}\right)$ do que na primavera $\left(23,6^{\circ} \mathrm{C}\right)$, com mínimas mais baixas registradas durante os meses de outubro $\left(15,7^{\circ} \mathrm{C}\right)$ e novembro $\left(18,5^{\circ} \mathrm{C}\right)$, e a maior máxima em fevereiro $\left(32,6^{\circ} \mathrm{C}\right)$.

A área total foi dividida em 22 piquetes de aproximadamente $682 \mathrm{~m}^{2}$ cada, dos quais oito foram usados no experimento. Foi adotado o delineamento em blocos ao acaso, em arranjo de parcelas subdivididas, com quatro repetições.
Os tratamentos consistiram de duas alturas de resíduo $(50$ e $100 \mathrm{~cm})$ alocadas às parcelas e, nas subparcelas, foram consideradas as classes de perfilhos segundo a sua origem (basais ou aéreos). O intervalo entre pastejos foi de 30 dias, realizados com vacas leiteiras mestiças Holandês x Zebu, com grupo genético de $50 \%$ a $80 \%$ da raça Holandesa. A taxa de lotação foi flexível e ajustada, quando necessário, com base de oferta de forragem estimada acima da meta de altura de resíduo pós-pastejo, um dia antes da entrada dos animais. A oferta foi estimada por meio de avaliações visuais comparativas (Cóser et al., 2002), tendo-se adotado como critério uma oferta mínima diária de forragem disponível de 3\% (kg de MS por $100 \mathrm{~kg}$ de peso vivo). Foram utilizadas vacas não lactantes (reguladoras) para ajustar as taxas de lotação.

O índice de área foliar (IAF) foi estimado em quatro piquetes (repetições), um dia antes da entrada dos animais (pré-pastejo), em cada ciclo de pastejo, por meio da amostragem de quatro touceiras por piquete, cortadas no nível do solo. As touceiras foram imediatamente pesadas e posteriormente fracionadas em perfilhos basais e aéreos e, de cada amostra, foram selecionadas duas subamostras com 20 perfilhos de cada classe, que foram separados em folhas (lâminas e bainhas) verdes, e as lâminas tiveram sua área foliar medida com integrador de área foliar (Leaf Area Metter LI-3100 Licor). Para estimar os valores de IAF médios do pasto, em cada época de amostragem, a área foliar média por perfilho basal e aéreo foi multiplicada por suas respectivas densidades populacionais (perfilhos por $\mathrm{m}^{2}$ ) (Carvalho et al., 2006).

A radiação fotossinteticamente ativa (RFA) interceptada pelo dossel foi estimada por meio de 20 leituras acima do dossel e 40 leituras em sua base (altura do solo), em cada piquete (repetição), um dia antes da entrada dos animais (pré-pastejo), tendo-se utilizado um sensor Quantum LI-190SA conectado a um medidor digital de radiação luminosa (LI-250, LI-COR, Inc.). As leituras foram feitas sempre no intervalo entre as 11 e as $13 \mathrm{~h}$ de cada dia, na condição de sol pleno, e somente nos momentos em que não havia interferência de nebulosidade. As medidas foram tomadas de forma sistemática, com uma régua de madeira graduada, com quatro metros de comprimento, em toda a área do piquete. As leituras feitas na base do dossel foram tomadas a cada quatro metros, no ponto exato (dentro ou fora da touceira) onde a extremidade da régua tocava 
o solo. As leituras feitas acima do dossel foram feitas à altura média de $2,5 \mathrm{~m}$, a cada duas leituras realizadas no nível do solo, sistematicamente, com o sensor preso à régua de madeira ( $8 \mathrm{~m}$ de distância). Com base nessas leituras, foram calculadas as diferenças, em porcentagem, entre as RFA acima e abaixo do dossel.

O coeficiente de extinção luminosa foi calculado segundo Sheehy \& Cooper (1973), com base na lei de Beer-Lambert, com a equação: $k_{2}=-\left[\log _{e}(R F A\right.$ incidente/RFA na base do solo)]/IAF, assumindo-se que dentro de um dossel forrageiro as folhas são distribuídas ao acaso.

As taxas de acúmulo de matéria seca de forragem $\left(\mathrm{kg} \mathrm{ha}^{-1} \mathrm{dia}^{-1}\right.$ ) foram calculadas por meio das avaliações do fluxo de tecidos (alongamento de folhas e de colmos e senescência) e das densidades populacionais de perfilhos, obtidas nos trabalhos de Carvalho et al. (2005b, 2006).

Para a análise de variância, foi utilizado o procedimento GLM (General Linear Models) do SAS (Statistical Analysis System), versão 6.03 (SAS Institute, 1998), com a opção medidas repetidas no tempo. As médias, estimadas pela opção LSMEANS, foram comparadas por meio da probabilidade da diferença entre elas (teste $t$ ), adotando-se um nível de probabilidade de 5\%.

\section{Resultados e Discussão}

Houve efeito de altura de resíduo $(p=0,0034)$, classe de perfilho $(p=0,0012)$, ciclo de pastejo $(p=0,0326)$ e das interações entre classe de perfilho e ciclo de pastejo ( $\mathrm{p}=0,0001$ ), altura do resíduo e classe de perfilho $(p=0,0002)$ e altura do resíduo, classe de perfilho e ciclo de pastejo $(p=0,0413)$. Esta última interação ocorreu, porque os valores de IAF de pastos manejados com $100 \mathrm{~cm}$ de resíduo pós-pastejo foram maiores $(\mathrm{p}<0,05)$ para perfilhos aéreos, durante o primeiro ciclo, semelhantes $(\mathrm{p}>0,05)$ aos basais, durante o segundo e terceiro ciclos, e novamente maiores $(\mathrm{p}<0,05)$ que estes, durante os três últimos ciclos (Tabela 1). Em pastos manejados com resíduo de $50 \mathrm{~cm}$, o IAF foi semelhante $(\mathrm{p}>0,05)$ entre classes de perfilho, durante o primeiro ciclo, maior $(\mathrm{p}<0,05)$ para perfilhos basais, durante o segundo e terceiro ciclos e para aéreos durante os três últimos ciclos de pastejo. Esse padrão de resposta, possivelmente, ocorreu em razão do maior aparecimento de perfilhos basais durante a primavera, sobretudo, em pastos manejados com resíduo baixo $(50 \mathrm{~cm})$, e de perfilhos aéreos durante o verão, principalmente para pastos manejados com resíduo alto $(100 \mathrm{~cm})$, verificados por meio das variações em densidade populacional de perfilhos (Carvalho et al., 2006).

Os maiores valores de IAF, verificados em ambas as alturas de resíduo em perfilhos aéreos, durante os três últimos ciclos de pastejo, em relação aos três ciclos anteriores (Tabela 1), foram determinados por maior superposição de folhas desses perfilhos nos estratos médio e superior da pastagem, resultantes de modificações na estrutura morfológica e na arquitetura do dossel, entre esses períodos, conforme já constatado em pastagens de outras gramíneas forrageiras tropicais (Fagundes et al., 1999; Brâncio et al., 2003). Os resultados obtidos evidenciam a importância de perfilhos aéreos para o IAF, em pastos de capim-elefante, uma vez que, durante o período de verão,

Tabela 1. Índice de área foliar (IAF) de perfilhos basais e aéreos, de pastos de capim-elefante cv. Napier manejados com 50 e $100 \mathrm{~cm}$ de resíduo pós-pastejo, avaliado na condição de pré-pastejo ${ }^{(1)}$.

\begin{tabular}{|c|c|c|c|c|}
\hline \multirow[t]{2}{*}{ Ciclo de pastejo ${ }^{(2)}$} & \multirow[t]{2}{*}{ Classe de perfilho } & \multicolumn{2}{|c|}{ Altura do resíduo $(\mathrm{cm})$} & \multirow[t]{2}{*}{ Média } \\
\hline & & 100 & 50 & \\
\hline \multirow[t]{2}{*}{1} & Basais & $0,82 \mathrm{Ba}(0,16)$ & $1,03 \mathrm{Aa}(0,16)$ & 0,93 \\
\hline & Aéreos & $1,63 \mathrm{Aa}(0,28)$ & $1,32 \mathrm{Aa}(0,28)$ & 1,48 \\
\hline \multirow{2}{*}{2} & Basais & $1,64 \mathrm{Aa}(0,21)$ & $2,54 \mathrm{Aa}(0,19)$ & 2,09 \\
\hline & Aéreos & $2,15 \mathrm{Aa}(0,37)$ & $0,13 \mathrm{Bb}(0,02)$ & 1,14 \\
\hline \multirow[t]{2}{*}{3} & Basais & $1,42 \mathrm{Aa}(0,24)$ & $2,16 \mathrm{Aa}(0,19)$ & 1,81 \\
\hline & Aéreos & $1,70 \mathrm{Aa}(0,17)$ & $0,22 \mathrm{Bb}(0,09)$ & 0,96 \\
\hline \multirow[t]{2}{*}{4} & Basais & $0,44 \mathrm{Ba}(0,01)$ & $0,35 \mathrm{Ba}(0,06)$ & 0,40 \\
\hline & Aéreos & $2,35 \mathrm{Aa}(0,14)$ & $1,50 \mathrm{Ab}(0,10)$ & 1,93 \\
\hline \multirow[t]{2}{*}{5} & Basais & $0,97 \mathrm{Ba}(0,37)$ & $0,78 \mathrm{Ba}(0,04)$ & 0,88 \\
\hline & Aéreos & $2,83 \mathrm{Aa}(0,16)$ & $1,47 \mathrm{Ab}(0,11)$ & 2,15 \\
\hline \multirow[t]{2}{*}{6} & Basais & $0,73 \mathrm{Ba}(0,17)$ & $0,76 \mathrm{Ba}(0,06)$ & 0,75 \\
\hline & Aéreos & $3,17 \mathrm{Aa}(0,16)$ & $1,98 \mathrm{Ab}(0,17)$ & 2,58 \\
\hline
\end{tabular}

(1)Médias em cada ciclo de pastejo seguidas por letras iguais, maiúsculas na coluna e minúsculas na linha, não diferem entre si pelo teste t, a 5\% de probabilidade; números entre parênteses indicam o erro-padrão da média. ${ }^{(2)}$ Ciclo 1: de 1o/10 a 3/11/2002; ciclo 2: de 3/11 a 6/12/2002; ciclo 3: de 6/12/2002 a 18/1/2003; ciclo 4: de 18/1 a 10/2/2003; ciclo 5: de 10/2 a 15/3/2003; ciclo 6: de 15/3 a 17/4/2003. 
esses foram responsáveis em média, por aproximadamente $75 \%$ da composição do IAF. Apesar disso, alguns cuidados devem ser tomados na interpretação dos resultados, pois, como o intervalo entre pastejos foi fixo (30 dias), é difícil determinar se não foi excessivamente longo (principalmente durante o período de verão), a ponto de o progressivo sombreamento ter inibido o aparecimento, bem como a expansão foliar nos perfilhos basais. A maior participação no IAF de perfilhos basais, durante o período de primavera é por si só bastante sugestiva das interações, observadas entre classes de perfilho e ciclo de pastejo (a primeira foi a época em que as variáveis ambientais ainda não eram totalmente favoráveis ao crescimento da planta e, portanto, os intervalos entre pastejos, mais longos que aqueles de verão, deveriam ser respeitados).

A interceptação da radiação fotossinteticamente ativa (RFA) foi influenciada pelo ciclo de pastejo $(\mathrm{p}=0,0001) \mathrm{e}$ pela interação entre altura do resíduo e ciclo de pastejo $(p=0,0150)$. Essa interação ocorreu em consequiência de os pastos manejados com $100 \mathrm{~cm}$ de resíduo pós-pastejo terem apresentado valores semelhantes àqueles manejados com $50 \mathrm{~cm}$ de resíduo durante o primeiro, segundo, terceiro e quinto ciclos; e os maiores $(\mathrm{p}<0,05)$ valores durante o quarto e sexto ciclos (Tabela 2). Isto se deve aos maiores valores de IAF verificados durante os três últimos ciclos (Tabela 1), bem como às possíveis modificações na arquitetura do dossel que interferira na interceptação da RAF pelo dossel forrageiro (Brown \& Blaser, 1968; Parsons et al., 1983).

Os valores médios de interceptação luminosa apresentaram correlação baixa $(r=0,63)$ e não significativa

Tabela 2. Radiação fotossinteticamente ativa interceptada pelo dossel (porcentagem da radiação incidente no topo do dossel), avaliada na condição de pré-pastejo, em pastos de capim-elefante cv. Napier manejados com 50 e $100 \mathrm{~cm}$ de resíduo pós-pastejo ${ }^{(1)}$.

\begin{tabular}{ccccc}
\hline Ciclo de pastejo $^{(2)}$ & \multicolumn{2}{c}{ Altura do resíduo $(\mathrm{cm})$} & Média & EPM $^{(3)}$ \\
\cline { 2 - 3 } & 100 & 50 & & \\
\hline 1 & $62,45 \mathrm{a}$ & $59,45 \mathrm{a}$ & 60,95 & 1,50 \\
2 & $71,20 \mathrm{a}$ & $75,82 \mathrm{a}$ & 73,51 & 3,59 \\
3 & $70,20 \mathrm{a}$ & $74,90 \mathrm{a}$ & 72,55 & 3,40 \\
4 & $84,85 \mathrm{a}$ & $69,67 \mathrm{~b}$ & 77,26 & 1,22 \\
5 & $91,42 \mathrm{a}$ & $91,70 \mathrm{a}$ & 91,56 & 1,11 \\
6 & $97,82 \mathrm{a}$ & $90,05 \mathrm{~b}$ & 93,93 & 0,39 \\
\hline
\end{tabular}

${ }^{(1)}$ Médias na linha seguidas por letras iguais não diferem entre si pelo teste t, a 5\% de probabilidade. ${ }^{(2)}$ Ciclo 1: de $1 \cong / 10$ a 3/11/2002; ciclo 2: de 3/11 a 6/12/2002; ciclo 3: de 6/12/2002 a 18/1/2003; ciclo 4: de 18/1 a 10/2/2003; ciclo 5: de 10/2 a 15/3/2003; ciclo 6: de 15/3 a 17/4/2003. ${ }^{(3)}$ Erro-padrão da média.
( $\mathrm{p}=0,0864)$ com aqueles de IAF, quando foram considerados todos os ciclos de pastejo. Isto provavelmente ocorreu, porque houve aumento nos valores médios de interceptação luminosa ao longo dos ciclos, mesmo naqueles em que os IAF médios do dossel decresceram, sobretudo, no quarto ciclo de pastejo (Tabelas 1 e 2). Este comportamento pode ter sido determinado, também, pela variação na contribuição de colmos e material morto na composição morfológica do pasto, a partir do quarto ciclo de pastejo (Carvalho et al., 2005a). Porém, quando considerados somente os três últimos ciclos de pastejo, verificou-se correlação alta $(r=0,99)$ e significativa $(\mathrm{p}=0,0525)$ entre os valores médios dessas variáveis, possivelmente em consequiência da maior concentração de folhas na porção superior do dossel, determinada pelo grande aparecimento de perfilhos aéreos durante esse período, conforme Carvalho et al. (2006).

As variações observadas nas correlações entre a interceptação da RFA e o IAF ocorreram pelo fato de a interceptação ser regulada, também, pela estrutura do pasto, pelo ângulo foliar e pela disposição das folhas no dossel (Verhagen et al., 1963; Brown \& Blaser, 1968), os quais se modificam durante as estações do ano, principalmente em pastagens de gramíneas forrageiras tropicais (Fagundes et al., 2001). Como exemplo dessas variações, verificou-se que, durante o segundo e sexto ciclos de pastejo, os pastos apresentaram IAF médios semelhantes (3,2 e 3,3, respectivamente) e as interceptações da RAF variaram de $73 \%$ para $94 \%$, respectivamente (Tabelas 1 e 2). Possivelmente, dentre os fatores que determinaram essa diferença na interceptação da RFA, aquele que mais contribuiu foi o grande aparecimento de perfilhos aéreos, e a consequiente produção de folhas destes no estrato superior de pastos, manejados em ambas as alturas de resíduo.

Novamente, é importante observar os possíveis efeitos da adoção de intervalos fixos entre pastejos sobre essa variável. Alguns autores têm observado que o momento ideal de desfolhação em algumas gramíneas tropicais, particularmente capins do gênero Panicum, está associado ao ponto em que o dossel intercepta $95 \%$ da luz incidente (Barbosa, 2004; Carnevalli et al., 2006). O aumento da quantidade de luz interceptada pelo dossel, ao longo dos ciclos (Tabela 2), sugere que, durante o período de tempo avaliado, o capim-elefante exigiria variações no intervalo entre pastejos, para que sua produtividade fosse maximizada.

O coeficiente de extinção luminosa $(\mathrm{k})$ foi afetado pela altura do resíduo $(p=0,0214)$, ciclo de pastejo $(p=0,0001)$ e pela interação entre altura do resíduo e ciclo de pastejo 
$(p=0,0001)$. A interação ocorreu em conseqüência de os pastos manejados com resíduo pós-pastejo baixo $(50 \mathrm{~cm})$ terem apresentado valores maiores $(p<0,05)$, durante $o$ segundo e terceiro ciclos de pastejo, valores semelhantes $(p>0,05)$ durante o primeiro, quarto e quinto ciclos, e valores menores $(\mathrm{p}<0,05)$ durante o sexto ciclo, em relação aos pastos manejados com $100 \mathrm{~cm}$ de resíduo pós-pastejo (Tabela 3). Isso deve ter ocorrido como consequiência da maior atenuação da RFA, incidente nos dosséis de pastos manejados com $50 \mathrm{~cm}$ de resíduo durante a primavera (primeiro, segundo e terceiro ciclos), e de pastos manejados com resíduo de $100 \mathrm{~cm}$ durante o verão (quarto, quinto e sexto ciclos), atenuação essa ocasionada, possivelmente, por uma maior densidade de folhas dispostas mais horizontalmente, de perfilhos basais e aéreos, respectivamente. Variações sazonais dos valores de $\mathrm{k}$ também são reportadas na literatura (Brown \& Blaser, 1968; Sheehy \& Cooper, 1973; Fagundes et al., 2001) e relacionadas, principalmente, às variações em estrutura do dossel forrageiro.

O progressivo aumento no coeficiente de extinção luminosa indica que ao longo dos ciclos de pastejo a folhagem dos pastos de capim-elefante adquiriu um arranjo mais horizontal, o que sugere uma importante mudança sazonal na arquitetura foliar dessa planta. Essa nova disposição espacial das folhas, possivelmente, foi determinada pela predominância de perfilhos aéreos, a partir do terceiro ciclo de pastejo (Carvalho et al., 2006), os quais possuem menor ângulo de inserção nos perfilhos principais (haste-mãe) que os basais e tornam a folhagem mais plana. Além disso, a distribuição de material morto, ao longo do dossel, também pode ter contribuído para esses resultados, uma vez que, apesar de não

Tabela 3. Coeficiente de extinção luminosa, estimado na condição de pré-pastejo, em pastos de capim-elefante cv. Napier, manejados com 50 e $100 \mathrm{~cm}$ de resíduo pós-pastejo ${ }^{(1)}$.

\begin{tabular}{ccccc}
\hline Ciclo de pastejo $^{(2)}$ & \multicolumn{2}{c}{ Altura do resíduo $(\mathrm{cm})$} & Média & EPM $^{(3)}$ \\
\cline { 2 - 3 } & 100 & 50 & & \\
\hline 1 & $0,41 \mathrm{a}$ & $0,39 \mathrm{a}$ & 0,40 & 0,27 \\
2 & $0,36 \mathrm{~b}$ & $0,55 \mathrm{a}$ & 0,45 & 0,31 \\
3 & $0,41 \mathrm{~b}$ & $0,59 \mathrm{a}$ & 0,50 & 0,35 \\
4 & $0,70 \mathrm{a}$ & $0,66 \mathrm{a}$ & 0,68 & 0,47 \\
5 & $0,80 \mathrm{a}$ & $0,82 \mathrm{a}$ & 0,81 & 0,58 \\
6 & $0,99 \mathrm{a}$ & $0,85 \mathrm{~b}$ & 0,92 & 0,62 \\
\hline
\end{tabular}

${ }^{(1)}$ Médias na linha seguidas por letras iguais não diferem entre si pelo teste t, a 5\% de probabilidade. ${ }^{(2)}$ Ciclo 1: de 1\%/10 a 3/11/2002; ciclo 2: de 3/11 a 6/12/2002; ciclo 3: de 6/12/2002 a 18/1/2003; ciclo 4: de 18/1 a 10/2/2003; ciclo 5: de 10/2 a 15/3/2003; ciclo 6: de 15/3 a 17/4/2003. (3)Erro-padrão da média. contribuírem para a formação do IAF, interceptam e atenuam a luz incidente.

A maior contribuição para a taxa de acúmulo de forragem foi proveniente dos perfilhos basais, durante quase todo o período experimental (Carvalho et al., 2005b). Apesar de parecer paradoxal em relação aos dados de IAF (para os quais os perfilhos aéreos foram os que mais contribuíram), isto pode ser explicado pela inclusão do componente colmo na taxa de acúmulo. Como os perfilhos basais servem de substrato e dão sustentação aos perfilhos aéreos, seria esperado que o componente colmo assumisse uma proporção maior na forragem acumulada nesse tipo de perfilho, comparativamente aos aéreos, o que de fato ocorreu (Carvalho et al., 2005b).

A associação desses dois fatores indica que uma grande proporção da forragem acumulada em capim-elefante pode ser oriunda do processo de alongamento de colmos, assim como observado em capim Tifton-85 por Pinto et al. (2001). Esse fato sugere que o intervalo adotado entre pastejos foi muito longo para maximizar a produção de forragem a ser aproveitada do capim-elefante, quando utilizado sob pastejo, particularmente durante o verão. Além disso, essa associação indica que experimentos com plantas forrageiras, em que combinações de freqüência e intensidade de pastejo são controladas, acrescentam informações mais precisas e menos casuísticas para o manejo do pastejo, conforme já demonstrado em trabalhos de Barbosa (2004) e Carnevalli et al. (2006).

De uma maneira geral, os resultados deste estudo revelaram que o conhecimento do comportamento do IAF, aliado àqueles da interceptação da RAF incidente e de variáveis relativas às características intrínsecas do dossel, como o coeficiente de interceptação luminosa, é essencial para esclarecer as variações em produtividade primária, ocorridas em pastos de capim-elefante.

\section{Conclusões}

1. A altura do resíduo influencia o índice de área foliar, a interceptação luminosa e seu coeficiente de extinção, em dosséis de pastos de capim-elefante.

2. O índice de área foliar e o acúmulo de forragem apresentam variações sazonais determinadas pelas classes de perfilhos basais e aéreos, além de também sofrerem influência direta do material morto do pasto e da presença de colmos.

3. Pastos de capim-elefante exigem variações no intervalo entre pastejos, ainda que dentro da mesma estação de crescimento. 


\section{Referências}

BARBOSA, R.A. Características morfofisiológicas e acúmulo de forragem em capim-tanzânia (Panicum maximum Jacq. cv. Tanzânia) submetido a freqüiências e intensidades de pastejo. 2004. 119p. Tese (Doutorado) - Universidade Federal de Viçosa, Viçosa.

BRÂNCIO, P.A.; EUCLIDES, V.P.B.; NASCIMENTO-JÚNIOR, D.; FONSECA, D.M. da; ALMEIDA, R.G. de; MACEDO, M.C.M.; BARBOSA, R.A. Avaliação de três cultivares de Panicum maximum Jacq. sob pastejo: disponibilidade de forragem, altura do resíduo pós-pastejo e participação de folhas, colmos e material morto. Revista Brasileira de Zootecnia, v.32, p.55-63, 2003.

BROUGHAM, R.W. Interception of light by the foliage of pure and mixed stands of pasture plants. Australian Journal of Agricultural Research, v.9, p.39-52, 1958.

BROWN, R.H.; BLASER, R.E. Leaf area index in pasture growth. Herbage Abstracts, v.38, p.1-9, 1968.

CARNEVALLI, R.A.; SILVA, S.C. da; BUENO, A.A.O.; UEBELE, M.C.; BUENO, F.O.; HODGSON, J.; SILVA, G.N.; MORAIS, J.P.G. Herbage production and grazing losses in Panicum maximum cv. Mombaça under four grazing managements. Tropical Grasslands, v.40, p.165-176, 2006.

CARVALHO, C.A.B. de; PACIULLO, D.S.C.; ROSSIELLO, R.O.P.; DERESZ, F. Composição morfológica da pastagem de capim-elefante em relação à altura de resíduo pós-pastejo e classes de perfilhos. Boletim de Indústria Animal, v.62, p.45-54, 2005a.

CARVALHO, C.A.B. de; PACIULLO, D.S.C.; ROSSIELLO, R.O.P.; DERESZ, F. Dinâmica do perfilhamento em capim-elefante sob influência da altura do resíduo pós-pastejo. Pesquisa Agropecuária Brasileira, v.41, p.145-152, 2006.

CARVALHO, C.A.B. de; PACIULLO, D.S.C.; ROSSIELLO, R.O.P.; DERESZ, F. Morfogênese do capim-elefante manejado sob duas alturas de resíduo pós-pastejo. Boletim de Indústria Animal, v.62, p.101-109, 2005b.

CÓSER, A.C.; MARTINS, C.E.; CARDOSO, F.P.N. Produção de leite em pastagem de capim-elefante submetida a duas alturas de resíduo pós-pastejo. Ciência e Agrotecnologia, v.25, p.417-423, 2001.

CÓSER, A.C.; MARTINS, C.E.; CARVALHO, C.A.B. de; GERÔNIMO, O.J.; FREITAS, V. de P.; SALVATI, J.A. Avaliação de metodologias para a estimativa da disponibilidade de forragem em pastagem de capim-elefante. Ciência e Agrotecnologia, v.26, p.589597, 2002.

DERESZ, F.; LOPES, F.C.F.; AROEIRA, L.J.M. Influência de estratégias de manejo em pastagem de capim-elefante na produção de leite de vacas Holandês x Zebu. Arquivo Brasileiro de Medicina Veterinária e Zootecnia, v.53, p.482-491, 2001.

EMBRAPA. Centro Nacional de Pesquisa de Solos (Rio de Janeiro, RJ). Sistema brasileiro de classificação de solos. Rio de Janeiro, 1999. 412p.

FAGUNDES, J.L.; SILVA, S.C. da; PEDREIRA, C.G.S.; CARNEVALLI, R.A.; CARVALHO, C.A.B. de; SBRISSIA, A.F.;
PINTO, L.F. de M. Índice de área foliar, coeficiente de extinção luminosa e acúmulo de forragem em pastagens de Cynodon spp. sob lotação contínua. Pesquisa Agropecuária Brasileira, v.36, p.187195,2001

FAGUNDES, J.L.; SILVA, S.C. da; PEDREIRA, C.G.S.; CARNEVALLI, R.A.; CARVALHO, C.A.B. de; SBRISSIA, A.F.; PINTO, L.F. de M. Intensidades de pastejo e a composição morfológica de pastos de Cynodon spp. Scientia Agricola, v.56, p.897-908, 1999.

HILLESHEIN, A.; CORSI, M. Capim-elefante sob pastejo: fatores que afetam as perdas e utilização de matéria seca. Pesquisa Agropecuária Brasileira, v.25, p.1233-1246, 1990.

LEMAIRE, G.; CHAPMAN, D. Tissue flows in plant communities. In: HODGSON, J.; ILLIUS, A.W. (Ed.). The ecology and management of grazing systems. Oxon: CAB International, 1996. p.3-36.

MIDDLETON, C.H. Dry matter and nitrogen changes in five tropical grasses influenced by cutting height and frequency. Tropical Grasslands, v.16, p.112-117, 1982.

NASCIMENTO JÚNIOR, D.; SILVA, S.C. da; ADESE, B. Perspectivas futuras do uso de gramíneas em pastejo. In: REUNIÃO ANUAL DA SOCIEDADE BRASILEIRA DE ZOOTECNIA, 41., 2004, Campo Grande. Anais. Campo Grande: SBZ, 2004. p.130141.

PACIULLO, D.S.C.; DERESZ, F.; AROEIRA, L.J.M.; MORENZ, M.J.F.; VERNEQUE, R.S. Morfogênese e acúmulo de biomassa foliar em pastagem de capim-elefante avaliada em diferentes épocas do ano. Pesquisa Agropecuária Brasileira, v.38, p.881-887, 2003.

PARSONS, A.J.; CHAPMAN, D.J. The principles of pasture and utilization. In: HOPKINS, A.(Ed.). Grass: its production \& utilization. Okehampton: British Grassland Society, 1998. p.31-80.

PARSONS, A.J.; LEAFE, E.L.; COLLET, B.; STILLES, W. The physiology of grass production under grazing. I. Characteristics of leaves and canopy photosynthesis of continuously grazed swards. Journal of Applied Ecology, v.20, p.117-126, 1983.

PINTO, L.F.M.; SILVA, S.C. da; SBRISSIA, A.F.; CARVALHO, C.A.B. de; CARNEVALLI, R.A.; FAGUNDES, J.L.; PEDREIRA, C.G.S. Dinâmica do acúmulo de matéria seca em pastagens de Tifton 85 sob pastejo. Scientia Agricola, v.58, p.439-447, 2001.

SAS INSTITUTE (Cary, Estados Unidos). SAS user's guide: release; version 6.03. Cary, 1998. 1028p.

SHEEHY, J.E.; COOPER, J.P. Light interception, photosynthetic activity, and crop growth rate in canopies of six temperate forage grasses. Journal of Applied Ecology, v.10, p.239-250, 1973.

VERHAGEN, A.M.; WILSON, J.H.; BRITTEN, E.J. Plant production in relation to foliage illumination. Annals of Botany, v.27, p.626-640, 1963.

WATSON, D.J. Comparative physiological studies on the growth of field crops. I. Variation in net assimilation rate and leaf area between species and varieties, and within and between years. Annals of Botany, v.11, p.41-76, 1947.

$\overline{\text { Recebido em } 20 \text { de julho de } 2006 \text { e aprovado em } 21 \text { de março de } 2007}$ 